\section{SERI delay}

Another three-month dclay has been announced by the Energy Research and Development Administration (ERDA) in the timetable for establishing the Solar Energy Research Institute (SERI), the facility which may eventually become the focal point for solar energy research in the United States. ERDA was hoping to choose a contractor to operate SERI and a site for the facility in December, but it now says that a decision cannot be made before March.

The delay stems chiefly from the fact that there is fierce competition among states for the contract to operate SERI, which will bring considerable amounts of federal money, jobs and prestige. ERDA has received 20 proposals for the contract and so far has climinated only one of them.

The three-month delay is only the latest in a scries of setbacks to the plans for SERI, first approved by Congress in November 1974.

\section{SGHWR report shortly}

Last week the final witnesses gave evidence on Britain's choice of nuclear reactor to the House of Commons Select Committee on Science and Technology. The committee says it hopes to publish its report in about a month, having questioned the Energy Minister $\mathrm{Mr}$ Benn, the Central Electricity Generating Board and the South of Scotland Elcctricity Board, the UK Atomic Energy Authority and the National Nuclear Corporation, and the Health and Safety Executive and Electrical Power Engineers Association.

Since the choicc of the British SteamGenerating Heavy Water Reactor two years ago it has undergone substantial modification (a reference design was only submitted in June of this year) and expenditure on it was deferred for a year in this summer's government spending cuts. Continuing doubts about whether it was the best choice made the committee decide to look at the whole question afresh.

\section{Protest over \\ Nacekuke closure}

Civil service unions are protesting to the Secretary of State for Defence about the plans to close the Chemical Defence Processing Establishment at Nancekuke, Cornwall-due, according to the unions, in March 1978. Some of the work of the station will be moved to Porton Down in Wiltshire, another defence establishment.

The union objects on the grounds that Nancekuke's function is the production of defence chemicals, a job that Porton Down, a primarily research establishment, is not equipped to do. According to the 1973 Nugent report, closing the station would save around $£ 80,000$ a year, mainly in administrative costs, but the unions claim that money would not be saved.
LEGISLATION to control toxic chemicals was as inescapable as are the facts that all substances are chemicals, all chemicals (depending on the level) are toxic, and all human activities are the target of regulation. Passage of the ncw law was accelerated by some notable gaffes by industry. Some of these mistakes were inadvertent because they preceded recent advances in toxicological testing. In other cases there was a reluctance to adopt known procedures in testing industrial compounds; some of these had long been obligatory for proposed new agricultural chemicals and food additives.

Insecticides bore the brunt of the earlier demands for increased regulation, perhaps because the methods used in applying insecticides were often easily visible, as when residential areas were sprayed to control mosquitoes. Conversely, food additives got into trouble with the public partly by heing honest. Their names are required on labels of foods in which they are put. Few scientists, and certainly no non-scientists, can derive a sense of epicurean satisfaction from contemplating the words "butylated hydroxytoluene" on the list of goodies in a prepared snack. Such nomenclature heightens the conviction that we are surrounded by a sea of new synthetic chemicals cven though our species has been sniffing and enjoying the odours of allyl isothiocyanate and diacetyl for many generations.
The new law should bring protection to workers in chemical factories. Vinyl chloride, kepone and dichloromethyl ether furnished three examples of inexcusable incidents in which such workers were exposed

\section{Curbing chemicals}

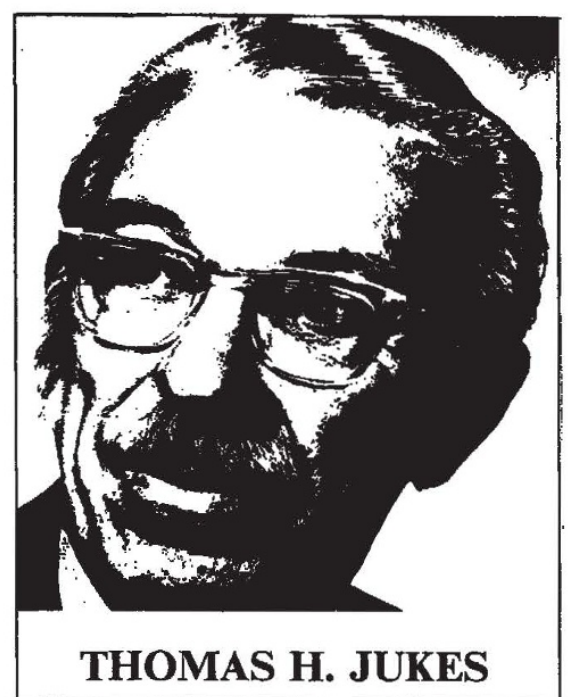

to toxic amounts of injurious chemicals. There is uncertainty and disagreement as to where the levels of such substances become tolerable, especially in the case of known or suspected carcinogens. However, it is known that the time of onset of cancer is lengthened by decreasing the dosage level, and lowering the dosage also decreases the probability that cancer will actually occur. These relationships apply regardless of whether or not an actual threshold can be established.

When the pressures for bans are examined and compared there are some interesting paradoxes. Polychlorinated biphenyls (PCBs) escaped scot-free for about eight years after it had been shown that they were environmental contaminants on a global scale, toxic at low levels to many vertebrates, and distributed without control. Their American manufacturer made small gestures such as taking PCBs out of "carbonless carbon paper". Their use continued in transformers and capacitors, which furnish, among other things, a comfortable living for the middle classes. But the fury of middle-class environmentalists descended on DDT, the use of which was primarily needed to save lives and prevent disease in disadvantaged countries. PCBs are far more stable than DDT and are known to be injurious to human beings as contaminants of cooking oil. Fortunately PCBs are on their way out, after being used as examples for the need of the new bill.

Let us hope that the aroused consciousness of possible injury from "new chemicals" will eventually result in a balanced study of hazards from both synthetic and "natural" compounds. In the meantime I am trying to avoid a feeling that $I$ am endangering myself when I sniff the smoke of a camp fire. 